\title{
Investigations of heating process and absorber materials in air heating collector
}

\author{
Aivars Aboltins*, Janis Palabinskis \\ Institute of Agricultural Machinery, Latvia University of Agriculture, Cakstes bulv. 5, Jelgava ,LV-3001, Latvia \\ "Corresponding author.Tel: +371 29134846,Fax:+37146 13211001,E-mail:aivars.aboltins@llu.lv
}

\begin{abstract}
The research had two aims-1 st. determine the airflow temperature distribution depending on the thickness of the collector air channel and collector length, where the absorber is a steel tinplate ; 2 nd. search non-traditional (utilized) materials (slices of black coloured beer cans, different size black colour seed boxes made of polypropylene) that could be used as absorbents of air heating solar collectors

$0.1 \times 0.5 \times 1.0$ meters long flat-plate collectors (FPC) for experimental research into the materials of solar air heating collector were built. The air velocity at the experiments was $\mathrm{v}=0.9 \mathrm{~m} / \mathrm{s}$, covered material - polystyrol plate. We used the sun following collectors, which guarantees perpendicular location of the plane of absorber from the flow of sun irradiance.

From the experimental data were obtained an analytical expressions that describe the solar radiation and collector air channel size influence to the flowing air temperature in FPC using steel tinplate absorber.

The panel of black colored slices of beer cans can be used for air heating solar collectors as absorber. The experimental data show the temperature difference in outlet of sun following collector reaches up to 10-11 degree with sun irradiance $1000 \mathrm{~W} / \mathrm{m}^{2}$ at different weather conditions. It is a little more better than the best seed boxes.
\end{abstract}

Keywords: Solar Collector, Air, Temperature, Absorber

\section{Introduction}

The greatest advantage of solar energy comparing with other forms of energy is that it is clean and can be supplied without environmental pollution. Over the past century, fossil fuels provided most of our energy, because it was much cheaper and more convenient than energy from alternative energy sources, and until recently, environmental pollution has been of little concern. The limited reserves of fossil fuels cause a situation in which the price of fuels will accelerate as the reserves are decreasing.

Solar energy is used to heat and cool buildings ( both actively and passively), dry products, heat water for domestic and industry use, heat swimming pools, generate electricity, for chemistry applications and many more operations [1].

The application of solar energy is completely dependent on solar radiation, a low-grade and fluctuating energy source. An intrinsic difficulty in using solar energy is caused by the wide variation in the solar radiation intensity. The availability of solar irradiance depends not only on the location, but also on the season. Extreme differences are experienced between summer and winter, and from day to day.

In general, solar water and solar air heaters are flat-plate collectors (FPCs), consisting of an absorber, a transparent cover, and backward insulation. Despite the similarity in designs, the different modes of operations and different properties of the heat transfer medium greatly affect the thermal performance and electric energy consumption for forcing the heat transfer medium a through the collector. Solar water heaters are operated as a closed-loop system whereas, in most cases, solar air heaters are operated in the open-loop mode. 
The performance of solar air heaters is mainly influenced by meteorological parameters (direct and diffuse radiation, ambient temperature, wind speed), design parameters (type of collector, collector materials) and flow parameters (air flow rate, mode of flow). The principal requirement of these designs is a large contact area between the absorbing surface and air.

The efficiency of solar collector depending on the collector covered materials (polyvinylchloride film, cell polycarbonate PC, translucent roofing slate) [2-5], absorbers (black colored wood, steel-thin plate etc.), with different air velocities in collector was investigated [6-9]. The main efficiency parameter of solar collector is the air heating degree and it we chose as a criterion of efficiency.

The plane of FPC absorber is perpendicular to the flow of sun irradiance at sun following collector therefore this type is more powerful than stationary collector. The sun rays fall under angle to collector plane (it means it falls under angle to covered material) and it gives more reflection.

For manufacturing of collectors it is important to know their thickness and its effect on the temperature distribution of heated air. As one of the best absorbers is a tin plate in the middle of collector, then it is interesting to know how heated air temperature changes above and below the plate.

There is a need to test the various, cheap, easily available materials in an absorbent material for manufacturing of solar collectors.

\section{Methodology}

In the laboratory a $0.1 \times 0.5 \times 1.0$ meters long experimental solar collectors were constructed for research into the properties of absorber materials. The air velocity at the experiments was $\mathrm{v}=0.9 \mathrm{~m} / \mathrm{s}$. Our investigations are devoted the sun following collectors, which guarantees perpendicular location of the plane of absorber from flow of the sun irradiance (Fig.1).

In the experiments, the collector covered material was a polystyrol plate. This material has gained immense popularity due to such properties as safety, mechanical crashworthiness, translucence and high UV radiation stability. The covered material - polystyrol plate reduced irradiance by $12-15 \%$.

The experimental data are recorded by means of an electronic metering and recording equipment of temperature, irradiance and lighting REG [10]. It is equipped with 16 temperature transducers and metering sensors of solar irradiance and lighting. The reading time of the data can be programmed from 1 to 99 minutes ( 1 minute in our case).

The recorded data are stored in the REG memory (there is a place for 16,384 records) and in case of need it is transferred to a computer for archiving with further processing. For evaluation and analysis of the results software REG - 01 has been developed, which is meant for transfer to the computer and processing of the recorded data. The information is stored in the form of a table and in case of need it is depicted as a graph. 
The air heating experiments by this collector were made at different weather conditions. The solar irradiance measuring instrument is a pyranometer. The data of sun irradiance are dependent on clouds, shadows and we aligned the experimental data with the method of least squares using Eq. (1) [11].

$$
\overline{y_{i}}=\frac{1}{35}\left[17 y_{i}+12\left(y_{i-1}+y_{i+1}\right)-3\left(y_{i-2}+y_{i+2}\right)\right]
$$

where $\overline{y_{i}}$ - aligned data, $y_{i}$ - experimental data, $i$ - index.

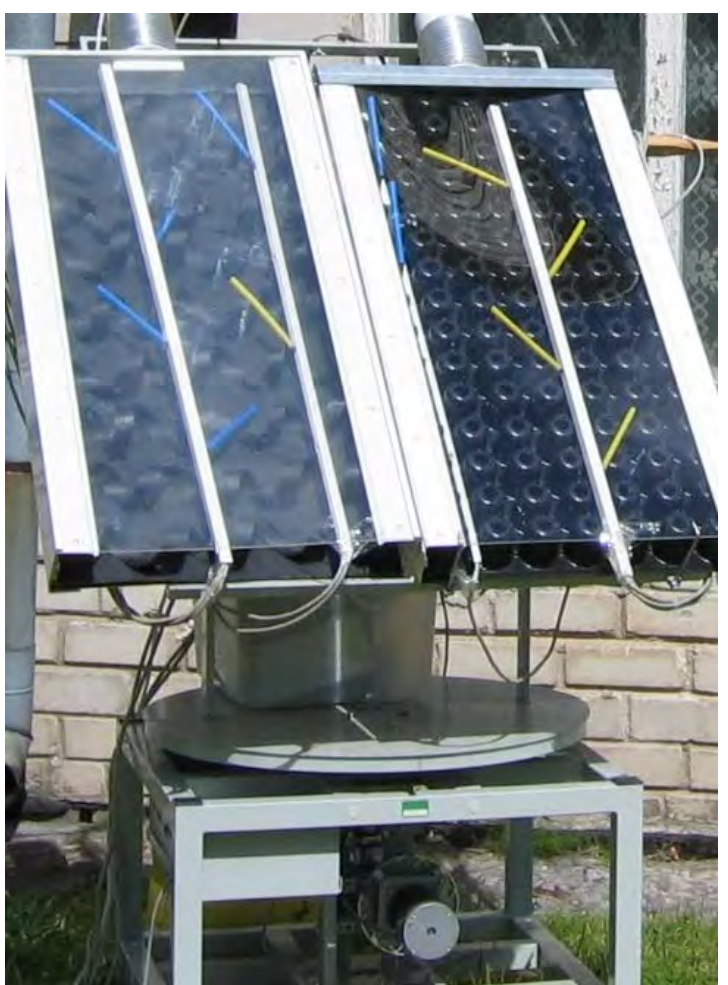

Fig. 1. Sun following collector at work

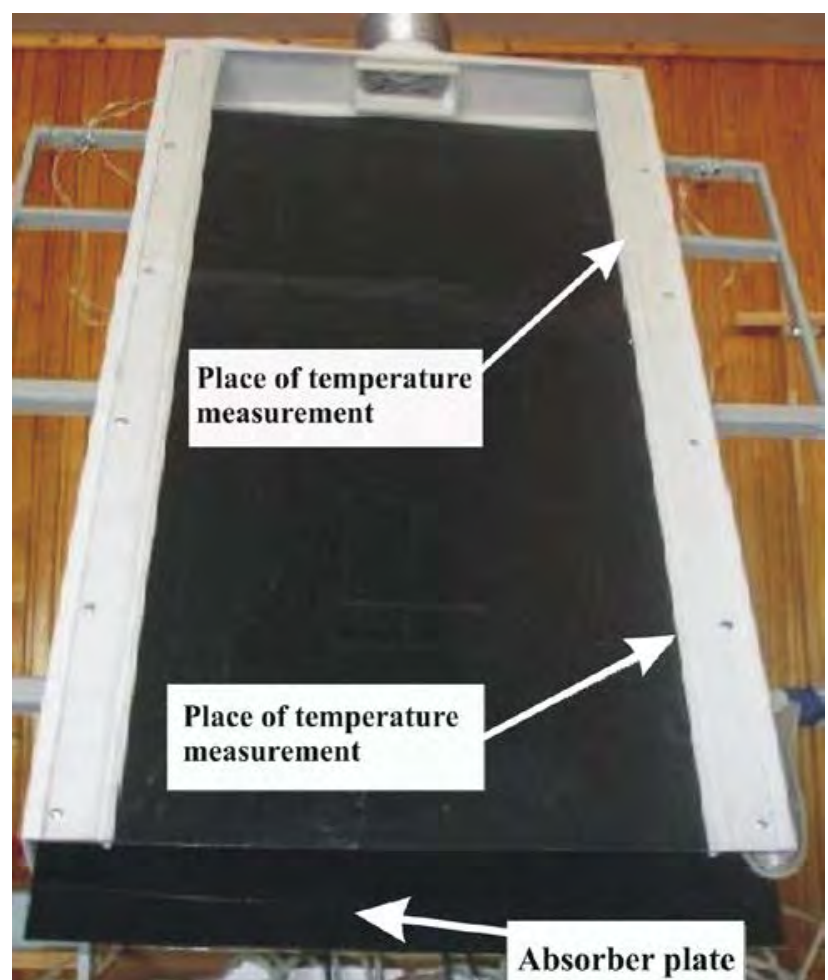

Fig. 2. View of solar collector with steel-tinplate absorber in middle.

\section{Results}

At first we researched a situation when the absorber (black coloured steel-thin plate) is put at the bottom and middle of the collector (Fig.2). Using the experimental results and statistical processing data we received correlation between the distance from absorber, sun irradiance to absorber plate and air temperature change in the collector. We got expressions for air temperature changing over steel-thin plate absorber in $\mathrm{FPC}$ at $35 \mathrm{~cm}$ and $60 \mathrm{~cm}$ from inlet.

The temperature change $\Delta \mathrm{T}$ over absorber at $0.35 \mathrm{~m}$ distance from input can be expressed with Eq. (2);

$$
\Delta T=3.8 \cdot 10^{-3} \cdot R+21.3 \cdot y-318.5 \cdot y^{2}-4.6 \cdot 10^{-3} \cdot R \cdot y,
$$

where y-distance from absorber, $(\mathrm{m}), \mathrm{R}$ - sun radiation $\left(\mathrm{W} / \mathrm{m}^{2}\right)$. 
Close connection of this expression and the experimental data shows coefficient of determination $\eta^{2}=0.804$ in temperature increase domain $\Delta T \in(0 ; 3){ }^{\circ} C$.

The temperature change $\Delta \mathrm{T}$ over absorber at $0.60 \mathrm{~m}$ from inlet we can be expressed with Eq.(3);

$$
\Delta T=1.57+0.011 \cdot R-4.15 \cdot 10^{-6} \cdot R^{2}-34.8 \cdot y+369.8 \cdot y^{2}-0.021 \cdot R \cdot y
$$

with coefficient of determination $\eta^{2}=0.855$.

The visual interpretation of expressions (2), (3) is shown in Fig.3-4.as contour plot .

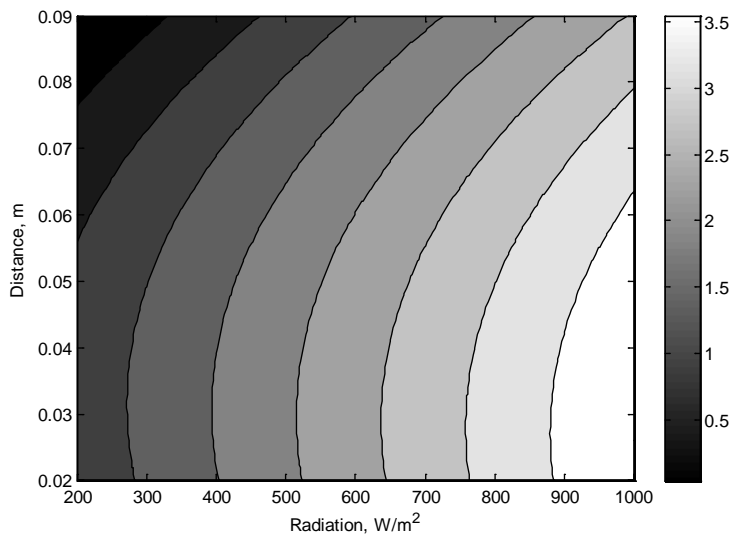

Fig. 3. Plot of air temperature increase $\Delta T$ depending on distance over absorber $y(m)$ and radiation $R\left(W / m^{2}\right)$ at $0.35 m$ from inlet

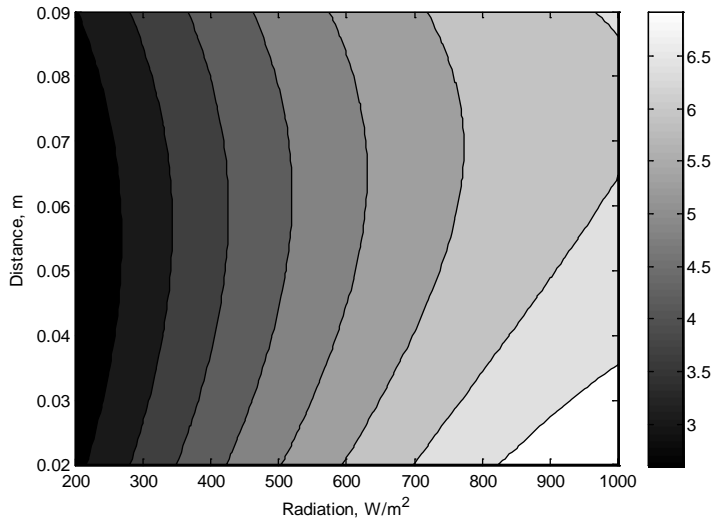

Fig. 4. Contour plot of air temperature increase $\Delta T$ depending on distance $y(m)$ over absorber and radiation of sun $R\left(W / m^{2}\right)$ at $0.6 \mathrm{~m}$ from inlet.

The temperature change $\Delta \mathrm{T}$ in the collector length over absorber (steel-tinplate) put in the middle of the air channel can be expressed with Eq. (4);

$\Delta T=0.0073 \cdot R-5.4 \times 10^{-6} R^{2}+17 \cdot x-25.6 \cdot x^{2}+0.028 \cdot R \cdot x$

where $\mathrm{x}$-length of collector, $(\mathrm{m})$. Coefficient of determination $\eta^{2}=0.98$ in temperature increase domain $\Delta T \in(0 ; 18){ }^{O} \mathrm{C}$.

The temperature change $\Delta \mathrm{T}$ in the collector under absorber can be expressed with Eq.(5) $\left(\Delta T \in(0 ; 10){ }^{O} C\right)$ :

$\Delta T=4.2 \cdot x-4.9 \cdot x^{2}-2.8 \times 10^{-3} \cdot R+3.4 \times 10^{-6} R^{2}+0.012 \cdot R \cdot x$,

with coefficient of determination $\eta^{2}=0.955$.

The graphical interpretation of these expressions is shown in Fig.5, Fig.6. 


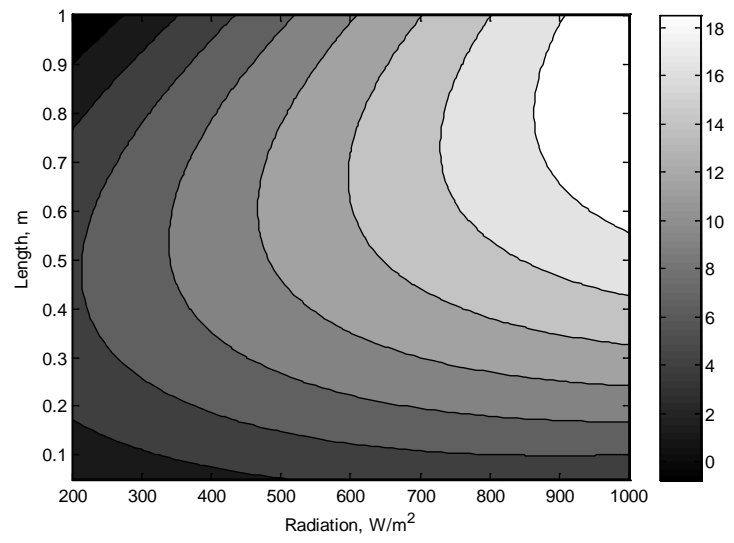

Fig. 5. Air temperature increase $\Delta T$ over steeltinplate absorber depending on collector length $x(m)$ and radiation $R\left(W / m^{2}\right)$

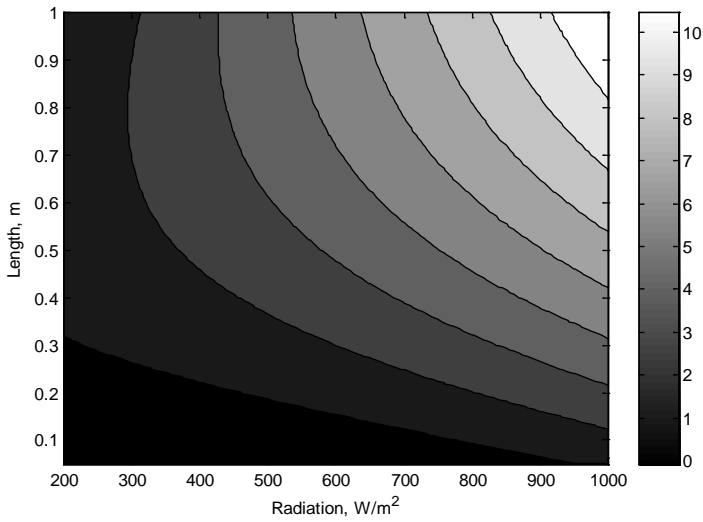

Fig. 6. Air temperature increase $\Delta T$ under steeltinplate absorber depending on collector length $x(m)$ and radiation $R\left(W / m^{2}\right)$

Second we tested new absorber materials which can be used in hand made air heated solar collectors. These materials must be cheap, light and simple use. We made panels with different size black seed boxes which were made of polypropylene (Fig.1, Fig.8) and a panel with coloured slices of beer cans (Fig.7, Fig.1). These slices help to mix the air flow in the collector and rise the outlet air temperature.

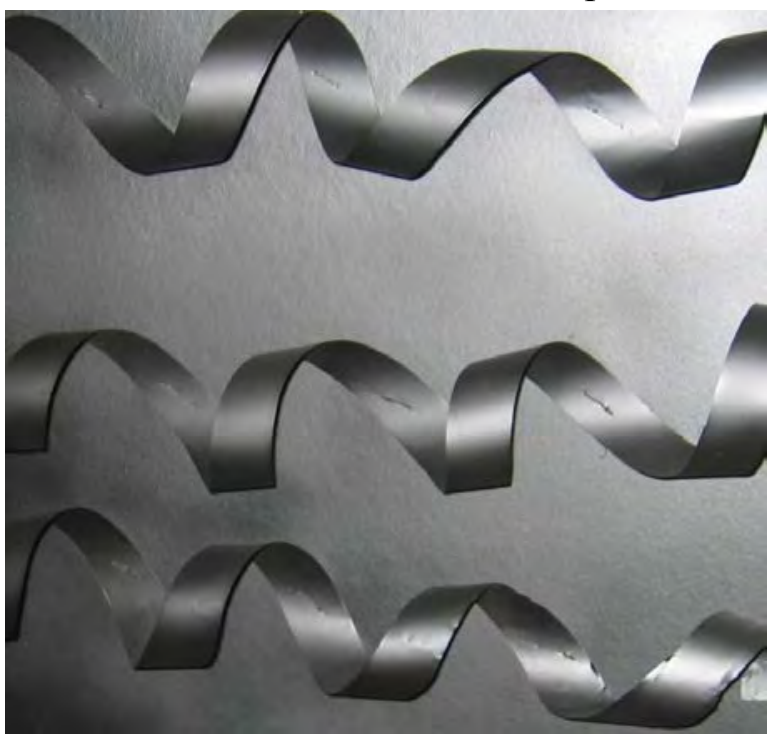

Fig.7 Black coloured slices of beer cans as absorbers of air collector

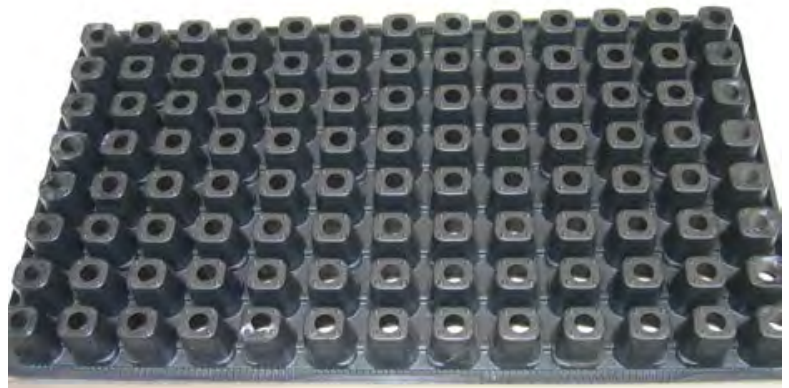

Fig.8 The panel of 13 seed boxes as absorbers of air collector

Air heating level is not highly dependent on ambient temperature. Much more it is influenced by solar radiation. Experimental results which was made in 7 .September 2010. showed it (Fig.9). 


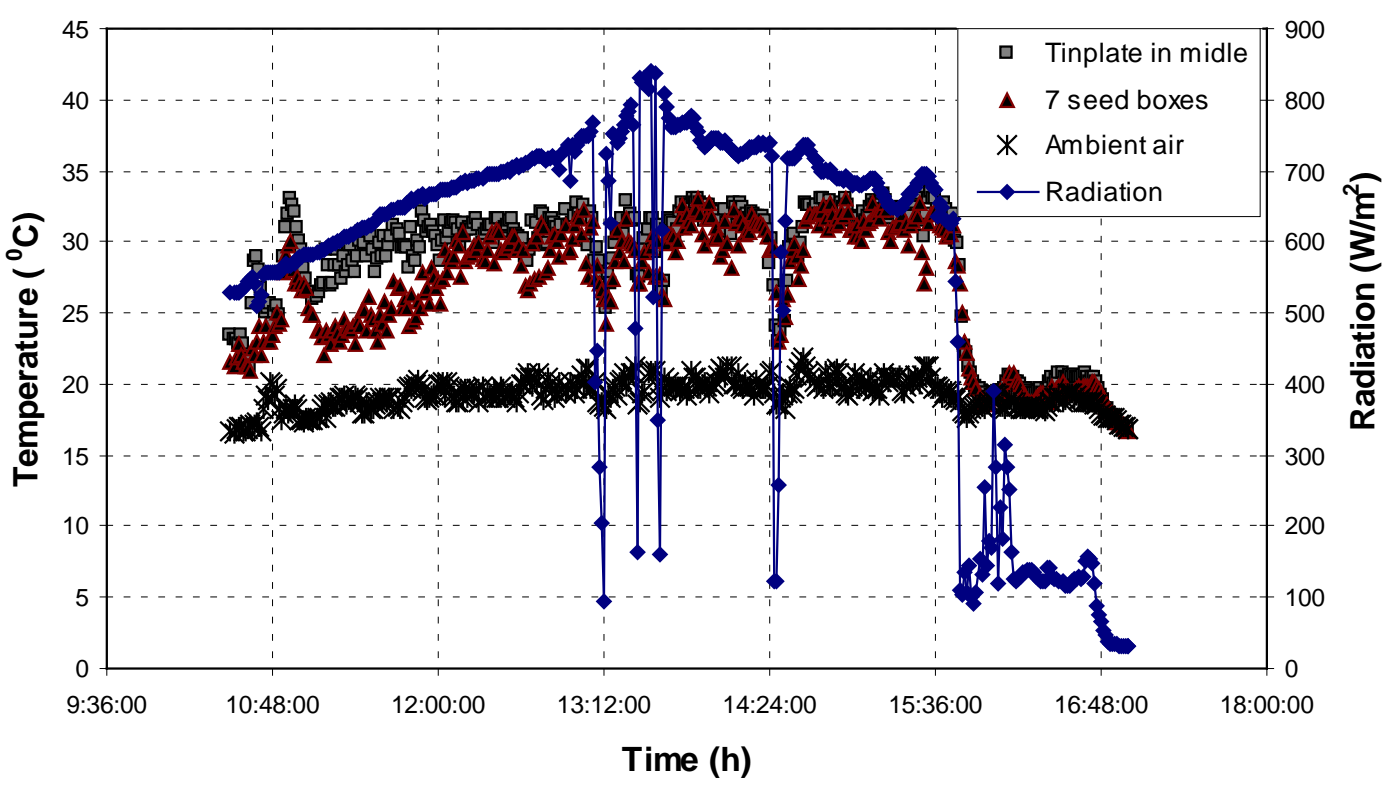

Fig.9 Ambient air, collectors( with tinplate, seed boxes absorbers) outlet temperatures and solar radiation changes (10:30-17:00 o'clock).

Ambient air heating degree serves as the main effectiveness of collectors at the same size collectors with the same fan power. Comparing the absorbers with 7 seed boxes in line (the best variant of seed boxes [8]) and the absorber panel with slices at the same weather conditions we can see that the absorber panel with slices of cans gives little bit better results (temperature increases at the outlet of collector) than the variant of seed boxes Fig.10. The air inflow temperature equal with ambient air temperature and it changed from $17{ }^{\circ} \mathrm{C}$ to 25 ${ }^{0} \mathrm{C}$ during the experiment.

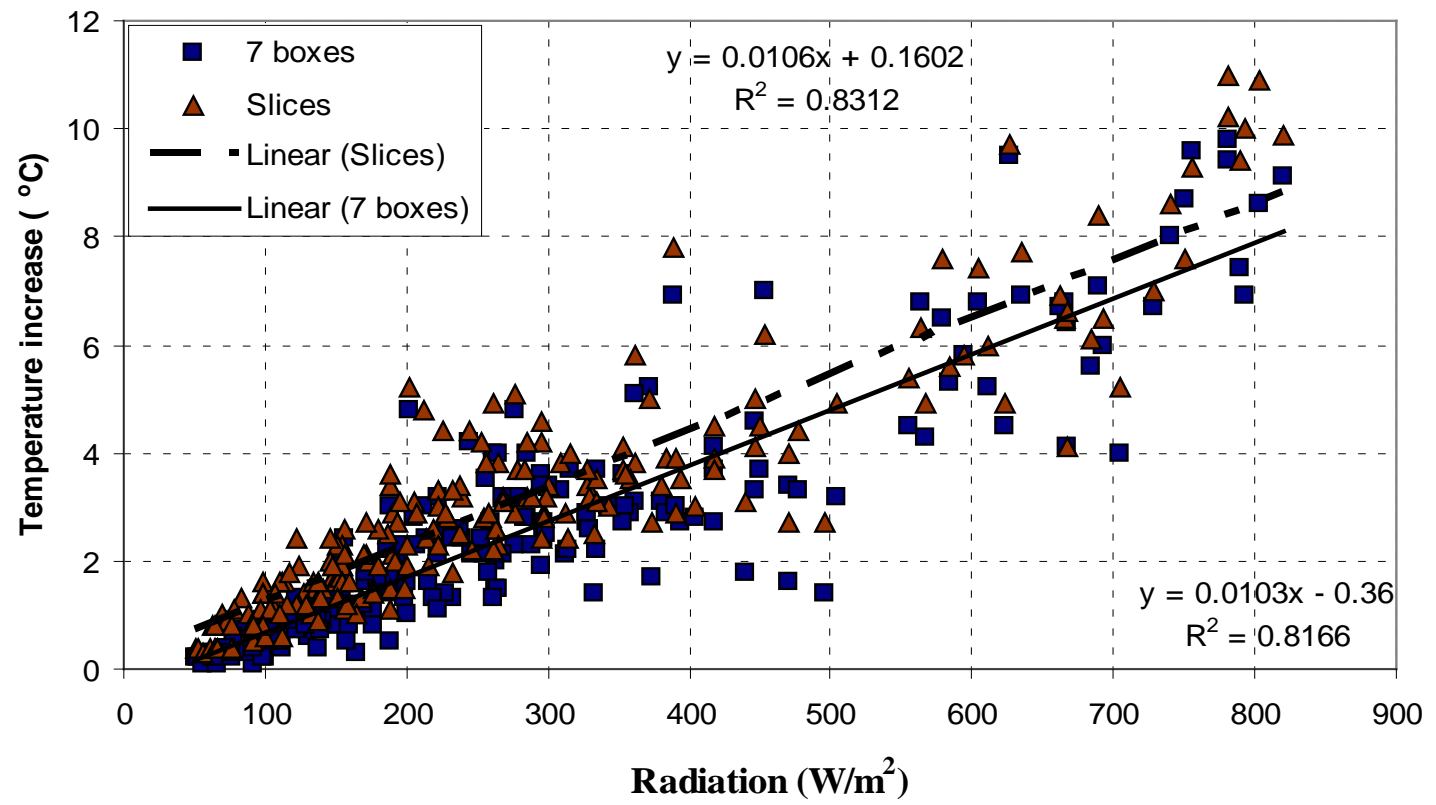

Fig.10 Air heating temperature difference with black coloured slices and 7 element seed boxes in line depending upon solar irradiance in sun following collector (11:00-18:00 o'clock). 
The experimental data show very good linear correlation between solar radiation and airheating degree (correlation coefficient greater than 0.9 ).

The efficiency of solar air collectors is influenced both by the design and air circulation and by the properties of the material used for cover, absorber and insulation. The efficiency of this absorber material can be explained by the type of absorber which mix the air flow in thickness and width of the collector area. It is important because without air mix, air exchange at corners and near sides of the collector does not take place.

\section{Conclusions}

1. The theoretical expressions for air temperature which are changing over steel-thin plate absorber in FPC at $35 \mathrm{~cm}$ and $60 \mathrm{~cm}$ from inlet are obtained. These expressions show temperature distribution depending on the distance to the absorbent tin plate and radiation.

2. Using experimental data processing temperature distribution above and below the absorbent sheet according to the length of the collector and solar radiation was obtained.

3. Absorber black colored slices of beer cans can be used for air heating solar collectors. The experimental data show that the temperature difference in outlet of sun following collector reaches up to $9-11$ degree with sun irradiance $1000 \mathrm{~W} / \mathrm{m}^{2}$ at different weather conditions.

4. Air solar collectors due to their physical and mechanical properties are suitable in Latvia for heating the air. At favorable weather conditions the heating degree of ambient air reaches more than 10 degrees at exit with the absorber length $1 \mathrm{~m}$ and air velocity $\mathrm{v}=0.9 \mathrm{~m} / \mathrm{s}$.

\section{References}

[1] S. Kalogirou Solar energy engineering: processes and systems, Academic Press Elsevier Inc. 2009.

[2] A.Lauva, A. Aboltins, J. Palabinskis, N. Karpova-Sadigova Comparative studies of the solar material collector, Proceedings of the 5th International Scientific Conference "Engineering for Rural Development “, 2006, pp.90-94

[3] A.Aboltins, J.Palabinskis, A.Lauva, J.Skujans, U.Iljins The material investigations of solar collector, Proceedings of the 6th International Scientific Conference "Engineering for Rural Development “, 2007, pp. 18-23

[4] J. Palabinskis, A. Aboltins, A. Lauva, N. Karpova-Sadigova The comparative material investigations of solar collector, Agronomy Research, Vol. 6, Engineering of Agricultural Technologies", 2008, pp.255-261

[5] J. Palabinskis, A. Lauva, A. Āboltinšs, N. Karpova-Sadigova. Movable Air Solar Collector and its Efficiency, 7th International Scientific Conference „Engineering for Rural Development”, 2008, pp 51 - 56 
[6] A. Aboltins, J. Palabinskis, A. Lauva, G. Rušķis The investigations of air solar collector efficiency, Proceedings of the 8th International Scientific Conference "Engineering for Rural Development “, 2009, pp.176-181

[7] A. Aboltins, J. Palabinskis, A. Lauva, G. Rušksis The steel-thin plate absorbers investigations in air solar collector, Proceedings of the 8th International Scientific Conference "Engineering for Rural Development “, 2009, pp.182-187

[8] A.Aboltins, J.Palabinskis, G. Rušksis Usage of different materials in air heated solar collectors, Proceedings of the 9th International Scientific Conference "Engineering for Rural Development “, 2010, pp.67-72

[9] A. Aboltins, J. Palabinskis, G. Rušķis. The investigations of heating process in solar heating collector, Agronomy Research, Vol. 8 „Biosystems Engineering”, 2010, pp.5 - 11

[10]REG Tehniskais apraksts un lietošanas pamācība (REG Technical description and using instruction), 2004, (in Latvian).

[11]Веденяпин Г.В. Общая методика экспериментального исследования и обработки опытных данных (The general methology of experimental research and treatment of experimental data). Колос, М.,1967, (in Russian) 